\title{
Income Is a Stronger Predictor of Mortality than Education in a National Sample of US Adults
}

\author{
Charumathi Sabanayagam ${ }^{1,2}$ and Anoop Shankar ${ }^{\prime}$ \\ 'Department of Community Medicine, West Virginia University School of Medicine, \\ Morgantown, WV 26506, USA and ${ }^{2}$ Singapore Eye Research Institute, Singapore
}

\begin{abstract}
Low socioeconomic status (SES) is associated with mortality in several populations. SES measures, such as education and income, may operate through different pathways. However, the independent effect of each measure mutually adjusting for the effect of other SES measures is not clear. The association between poverty-income ratio (PIR) and education and all-cause mortality among 15,646 adults, aged >20 years, who participated in the Third National Health and Nutrition Examination Survey in the USA, was examined. The lower PIR quartiles and less than high school education were positively associated with allcause mortality in initial models adjusting for the demographic, lifestyle and clinical risk factors. After additional adjustment for education, the lower PIR quartiles were still significantly associated with all-cause mortality. The multivariable odds ratio (OR) [95\% confidence interval (CI)] of all-cause mortality comparing the lowest to the highest quartile of PIR was 2.11 (1.52-2.95, p trend $\leq 0.0001)$. In contrast, after additional adjustment for income, education was no longer associated with all-cause mortality [multivariable OR $(95 \% \mathrm{CI})$ of all-cause mortality comparing less than high school to more than high school education was $1.05(0.85-1.31$, $\mathrm{p}$ trend=0.57)]. The results suggest that income may be a stronger predictor of mortality than education, and narrowing the income differentials may reduce the health disparities.
\end{abstract}

Key words: Education; Income; Inequality; Mortality; Risk factors; Socioeconomic conditions; United States

\section{INTRODUCTION}

Socioeconomic inequalities in health are a major public-health concern. Epidemiological studies have shown that socioeconomic status (SES) is associated with mortality in several populations (1-10). Although SES measures, such as education and income, are correlated to each other, they may also have an independent effect on mortality $(11,12)$. Thus, studying the role of each SES measure on mortality after mutually adjusting for other SES measures is necessary to understand the independent role of social differentials in mortality. In this context, we examined the independent effect of education and income on mortality by simultaneously adjusting for each other, in addition to the demographic, lifestyle and clinical factors.

\footnotetext{
Correspondence and reprint requests should be addressed to:

Dr. Anoop Shankar

Department of Medicine

West Virginia University School of Medicine

PO Box 9190

Morgantown, WV 26506-9190

USA

Email: ashankar@hsc.wvu.edu

Fax: (304) 293-6685
}

\section{MATERIALS AND METHODS}

The Third National Health and Nutrition Examination Survey (NHANES III) collected data on a nationwide probability sample of the civilian noninstitutionalized US population. Detailed descriptions of the complex survey design, interviewing procedures, and physical examinations conducted have been published before and are available online (13).

Information on mortality status was available for 18,800 participants aged $\geq 20$ years. We further excluded those with missing data on poverty-income ratio (PIR, $n=1,978)$, education ( $n=96)$, and other variables $(\mathrm{n}=1,080)$ included in the multivariable model, leaving 15,646 available for current analysis. Compared to those who were included in the final analysis, those who were excluded $(n=3,154)$ were: older, more likely to be female, primary or below educated, to have lower PIR, less likely to be non-Hispanic whites, consume alcohol, physically active, and had higher levels of mean arterial blood pressure (MABP) (all $\mathrm{p}<0.05)$.

The main outcome of interest-all-cause mortality - was recorded from the NHANES III-linked 
mortality file provided by the National Center for Health Statistics (NCHS). The participants were followed up for mortality for up to 12 years from 1988-1994 through 31 December 2006. Ascertainment of mortality was based upon a probabilistic match between the NHANES III and the death certificate records of the National Death Index. Education and PIR were chosen as indicators of SES. PIR was computed as a ratio of the mid-point of the observed family-income category to the family's appropriate poverty threshold set by the US Census Bureau in a given calendar year. The educational status based on completed years of education was categorized into $<$ high school graduate $(<12$ years), high school graduate (12 years), and $>$ high school graduate $(>12$ years, including college degree).

We first examined the association between PIR and all-cause mortality and subsequently examined the association between education and all-cause mortality. To examine the independent effect of education and income on all-cause mortality, we used three logistic regression models: (a) the age, sex-adjusted model; (b) the multivariable-adjusted model 1 , additionally adjusting for race-ethnicity, marital status, smoking, alcohol intake, physical activity, MABP, body mass index, high-density lipoprotein cholesterol, and (c) the multivariable-adjusted model 2, adjusting for all variables in the multivariable model 1 plus mutual adjustment of other SES measures (education in models of PIR and PIR in models of education). The trends in the odds ratio (OR) of all-cause mortality across the categories of PIR and education were tested by modelling each SES indicator category as an ordinal variable in the corresponding multivariable model. In subgroup analyses, we examined the association among education, income, and all-cause mortality stratified by race-ethnicity and gender using the multivariable model 2. All analyses were weighted to account for unequal probabilities of selection, oversampling, and non-response using the SUDAAN software (version 8.0) (Research Triangle Institute, Research Triangle Park, NC) and the SAS software (version 9.2) (SAS Institute, Cary, NC).

\section{Ethical approval}

Participants signed an informed consent form before interview in the home. The ethical approval was obtained from the Institutional Review Board of the National Center for Health Statistics of the Centers for Disease Control and Prevention.

\section{RESULTS}

Table 1 shows the ORs for mortality in relation to selected factors included in the multivariable model. Age, race-ethnicity, being never married, and former and current smoking were positively associated with all-cause mortality whereas female sex, current drinking, and physical activity were inversely associated with all-cause mortality. Table 2 shows the association among PIR and education and all-cause mortality. The lower PIR quartiles were positively associated with mortality in both age, sex-adjusted model and multivariable model 1 that was additionally adjusted for the demographic, lifestyle and clinical risk factors ( $p$ trend $<0.0001$ ). Additional adjustment for education in the multivariable model 2 , though attenuated this association, it still remained significant ( $p$ trend $<0.0001$ ). Education was associated with mortality in the age, sex-adjusted model and in the multivariable model 1 ( $\mathrm{p}$ trend=0.0006). Additional adjustment for income in the multivariable model 2 , however, weakened this association considerably, and it was no longer significant ( $p$ trend $=0.57$ ).

Table 3 shows the association between the SES and all-cause mortality in subgroups of race-ethnicity and gender. In general, the positive association between lower PIR and mortality was consistently present in categories of gender and race-ethnicity. Consistent with the main findings, the association between education and all-cause mortality was not significant in either men or women. When stratified by race-ethnicity, the association between education and all-cause mortality was not significant in non-Hispanic whites but was stronger in other race-ethnicities. However, there was no significant interaction by race-ethnicity ( $\mathrm{p}$-interaction $=0.3$ ).

\section{DISCUSSION}

In a contemporary, multi-ethnic sample of US adults, we found that the lower PIR quartiles were positively associated with all-cause mortality, independent of the demographic, lifestyle and clinical risk factors. This association was persistent after additional adjustment for education and was consistently present in subgroups of gender and raceethnicity. In contrast, education was not associated with all-cause mortality after additional adjustment for income.

The majority of the US studies that examined the association between the SES and mortality have used education $(5,6)$ or income $(7,8)$ as measures of SES. The results of our study suggest that income was independently associated with mortality after accounting for the effect of education. In the Americans' Changing Lives Survey, income differentials in mortality persisted after accounting for education and behavioural factors (7). Similarly, it was shown that income overrides the effect of education and occupation on mortality among a large cohort of insurance enrollees in Germany (14). A 


\begin{tabular}{|c|c|c|}
\hline Characteristics & $\begin{array}{c}\text { Multivariable OR } \\
(95 \% \mathrm{CI})\end{array}$ & $\mathrm{p}$ value \\
\hline \multicolumn{3}{|l|}{ Model significance } \\
\hline Female & $0.59(0.50-0.69)$ & $<0.0001$ \\
\hline \multicolumn{3}{|l|}{ Race } \\
\hline Non-Hispanic whites & 1.00 (Reference) & \\
\hline Non-Hispanic blacks & $1.24(0.95-1.62)$ & 0.1 \\
\hline Mexican Americans & $1.04(0.82-1.32)$ & 0.7 \\
\hline Others & $0.41(0.22-0.75)$ & 0.004 \\
\hline \multicolumn{3}{|l|}{ Marital status } \\
\hline Married/living as married & 1.00 (Reference) & \\
\hline Never married & $1.34(1.02-1.76)$ & 0.03 \\
\hline Others & $1.48(0.99-2.21)$ & 0.05 \\
\hline \multicolumn{3}{|l|}{ Smoking categories } \\
\hline Never & 1.00 (Reference) & \\
\hline Former & $1.47(1.20-1.80)$ & 0.0002 \\
\hline Current & $2.25(1.75-2.91)$ & $<0.0001$ \\
\hline Alcohol drinking & $0.76(0.60-0.96)$ & 0.01 \\
\hline Physical activity & $0.65(0.54-0.78)$ & $<0.0001$ \\
\hline Age, per unit increase & $1.10(1.09-1.11)$ & $<0.0001$ \\
\hline Mean arterial BP, per $10 \mathrm{~mm} \mathrm{Hg}$ increase & $1.01(1.00-1.01)$ & 0.08 \\
\hline Body mass index $\left(\mathrm{kg} / \mathrm{m}^{2}\right)$, per unit increase & $1.00(1.00-1.00)$ & 0.1 \\
\hline HDL-cholesterol (mg/dL), per 10 units decrease & $1.01(0.95-1.08)$ & 0.7 \\
\hline
\end{tabular}

Table 2. Association between socioeconomic status and mortality

\begin{tabular}{|c|c|c|c|c|c|}
\hline SES measure & $\begin{array}{c}\text { No. } \\
(n=15,646)\end{array}$ & $\begin{array}{l}\text { Mortality } \\
\text { rate (\%) }\end{array}$ & $\begin{array}{l}\text { Age and sex } \\
\text { adjusted } \\
\text { OR }(95 \% \text { CI) }\end{array}$ & $\begin{array}{l}\text { Multivariable } \\
\text { model 1* } \\
\text { OR }(95 \% \text { CI })\end{array}$ & $\begin{array}{c}\text { Multivariable } \\
\text { model } 2 \dagger \\
\text { OR }(95 \% \text { CI })\end{array}$ \\
\hline \multicolumn{6}{|l|}{$\begin{array}{l}\text { Poverty-income ratio } \\
\text { quartiles }\end{array}$} \\
\hline Quartile 4 (3.4-11.9) & 3,943 & 6.6 & 1.00 (referent) & 1.00 (referent) & 1.00 (referent) \\
\hline Quartile 3 (2.1-3.3) & 4,015 & 8.1 & $1.14(0.94-1.39)$ & $1.03(0.83-1.28)$ & $1.01(0.81-1.26)$ \\
\hline Quartile $2(1.2-2.0)$ & 3,834 & 14.9 & $1.94(1.56-2.42)$ & $1.75(1.39-2.21)$ & $1.73(1.34-2.23)$ \\
\hline Quartile 1 (0-1.1) & 3,854 & 15.0 & $2.86(2.15-3.82)$ & $2.14(1.58-2.90)$ & $2.11(1.52-2.95)$ \\
\hline $\mathrm{p}$ trend & & & $<0.0001$ & $<0.0001$ & $<0.0001$ \\
\hline \multicolumn{6}{|l|}{ Education } \\
\hline >high school & 4,579 & 5.7 & 1.00 (referent) & 1.00 (referent) & 1.00 (referent) \\
\hline High school & 4,843 & 8.8 & $1.40(1.15-1.71)$ & $1.23(1.01-1.50)$ & $1.15(0.95-1.39)$ \\
\hline$<$ high school & 6,224 & 18.0 & $1.67(1.37-2.03)$ & $1.32(1.08-1.61)$ & $1.05(0.85-1.31)$ \\
\hline $\mathrm{p}$ trend & & & $<0.0001$ & 0.006 & 0.57 \\
\hline \multicolumn{6}{|c|}{$\begin{array}{l}\text { *Adjusted for age (years), sex (women, men), race-ethnicity (non-Hispanic whites, non-Hispanic blacks, } \\
\text { Mexican Americans, others), marital status (married/living as married, never married, others), smoking } \\
\text { categories (never, former, current), current drinker (absent, present), mean arterial blood pressure (mm } \\
\text { Hg), high-density lipoprotein cholesterol (mg/dL), body mass index }\left(\mathrm{kg} / \mathrm{m}^{2}\right) \text {, and physical activity } \\
\text { (absent, present); } \dagger \text { Adjusted for all variables in multivariable model } 1+\mathrm{mutual} \text { adjustment of } \\
\text { SES variable (education in models of poverty-income ratio and vice-versa); CI=Confidence interval; } \\
\text { OR=Odds ratio; SES=Socioeconomic status }\end{array}$} \\
\hline
\end{tabular}




\begin{tabular}{|c|c|c|c|c|}
\hline \multirow[b]{2}{*}{ SES measure } & \multicolumn{2}{|c|}{$\begin{array}{l}\text { Multivariable } \\
\text { OR }(95 \% \text { CI })^{*}\end{array}$} & \multicolumn{2}{|c|}{$\begin{array}{l}\text { Multivariable } \\
\text { OR }(95 \% \text { CI })^{*}\end{array}$} \\
\hline & $\begin{array}{c}\text { Non-Hispanic } \\
\text { whites } \\
(\mathrm{n}=6,993)\end{array}$ & $\begin{array}{c}\text { Other } \\
\text { race-ethnicities } \\
(\mathrm{n}=8,653)\end{array}$ & $\begin{array}{c}\text { Men } \\
(\mathrm{n}=7,414)\end{array}$ & $\begin{array}{l}\text { Women } \\
(\mathrm{n}=8,232)\end{array}$ \\
\hline \multicolumn{5}{|c|}{ Poverty-income ratio } \\
\hline Quartile 4 & 1.00 (referent) & 1.00 (referent) & 1.00 (referent) & 1.00 (referent) \\
\hline Quartile 3 & $0.97(0.77-1.23)$ & 1.19 (0.71-1.99) & $1.17(0.86-1.60)$ & $0.83(0.59-1.15)$ \\
\hline Quartile 2 & $1.73(1.29-2.31)$ & $1.61(1.09-2.36)$ & $1.97(1.45-2.68)$ & $1.44(0.96-2.16)$ \\
\hline Quartile 1 & $2.29(1.52-3.43)$ & $1.68(1.05-2.69)$ & $2.69(1.69-4.28)$ & $1.62(1.10-2.40)$ \\
\hline $\mathrm{p}$ trend & $<0.0001$ & 0.03 & $<0.0001$ & 0.009 \\
\hline \multicolumn{5}{|l|}{ Education } \\
\hline >high school & 1.00 (referent) & 1.00 (referent) & 1.00 (referent) & 1.00 (referent) \\
\hline high school & $1.12(0.89-1.41)$ & $1.32(0.88-1.98)$ & $1.29(1.05-1.60)$ & $1.03(0.76-1.40))$ \\
\hline$<$ high school & $0.96(0.74-1.24)$ & $1.66(1.03-2.68)$ & $0.95(0.70-1.27)$ & $1.16(0.86-1.57)$ \\
\hline $\mathrm{p}$ trend & 0.71 & 0.03 & 0.66 & 0.30 \\
\hline
\end{tabular}

study in the USA that assessed insurance as an SES measure reported that lack of insurance was associated with mortality after adjustment for education and income (10). Income provides opportunities for healthy lifestyle, spending power, better housing, and access to medical care $(12,15,16)$. In the present study, education was not associated with mortality after accounting for income, suggesting that the educational differences in mortality may partly be mediated through the differences in income, consistent with previous reports $(7,17)$.

\section{Limitations}

Although the strengths of the study include its large sample-size, rigorous methodology, and rich information on covariates, our study has some limitations. First, since the SES variables were assessed only once as part of the NHANES III, the effect of changes in income over time on mortality could not be studied. Second, the possibility of residual confounding due to measurement error resulting from broad categorization of covariates, for example smoking and drinking, cannot be excluded.

\section{Conclusions}

In a nationally-representative sample of US adults, we found that lower income was positively associated with mortality, independent of the demo- graphic, lifestyle and clinical risk factors, and this association persisted after additional adjustment for education. In contrast, after additional adjustment for income, lower education was not associated with mortality. Our results suggest that income may be a stronger predictor of mortality than education, and narrowing the income differentials may reduce health disparities.

\section{ACKNOWLEDGEMENTS}

The study was funded by an American Heart Association National Clinical Research program grant (AS).

\section{REFERENCES}

1. Steenland K, Henley J, Calle E, Thun M. Individualand area-level socioeconomic status variables as predictors of mortality in a cohort of 179,383 persons. Am J Epidemiol 2004;159:1047-56.

2. Khang YH, Kim HR. Explaining socioeconomic inequality in mortality among South Koreans: an examination of multiple pathways in a nationally representative longitudinal study. Int J Epidemiol 2005; 34:630-7.

3. van Oort FV, van Lenthe FJ, Mackenbach JP. Material, psychosocial, and behavioural factors in the explanation of educational inequalities in mortality in 
the Netherlands. J Epidemiol Community Health 2005; 59:214-20.

4. Stringhini S, Sabia S, Shipley M, Brunner E, Nabi H, Kivimaki $\mathrm{M}$ et al. Association of socioeconomic position with health behaviors and mortality. JAMA 2010;303:1159-66.

5. Elo IT, Preston SH. Educational differentials in mortality: United States, 1979-85. Soc Sci Med 1996;42:4757.

6. Jemal A, Thun MJ, Ward EE, Henley SJ, Cokkinides VE, Murray TE. Mortality from leading causes by education and race in the United States, 2001. Am J Prev Med 2008;34:1-8.

7. Lantz PM, House JS, Lepkowski JM, Williams DR, Mero RP, Chen J. Socioeconomic factors, health behaviors, and mortality: results from a nationally representative prospective study of US adults. JAMA 1998;279:1703-8.

8. Rehkopf DH, Berkman LF, Coull B, Krieger N. The non-linear risk of mortality by income level in a healthy population: US National Health and Nutrition Examination Survey mortality follow-up cohort, 1988-2001. BMC Public Health 2008;8:383.

9. Sorlie PD, Backlund E, Keller JB. US mortality by economic, demographic, and social characteristics: the National Longitudinal Mortality Study. Am J Public Health 1995;85:949-56.

10. Wilper AP, Woolhandler S, Lasser KE, McCormick D, Bor DH, Himmelstein DU. Health insurance and mortality in US adults. Am J Public Health 2009;99:228995.
11. Krieger N, Williams DR, Moss NE. Measuring social class in US public health research: concepts, methodologies, and guidelines. Annu Rev Public Health 1997;18:341-78.

12. Liberatos P, Link BG, Kelsey JL. The measurement of social class in epidemiology. Epidemiol Rev 1988;10:87121.

13. National Center for Health Statistics. The Third national health and nutrition examination survey (NHANES III, 1988-1994): reference manuals and reports. Hyattsville, MD: Centers for Disease Control and Prevention, 1996. (www.cdc.gov/nchs/data/ nhanes/nh3rrm htm, accessed on 27 May 2010).

14. Geyer S, Peter R. Income, occupational position, qualification and health inequalities-competing risks? (comparing indicators of social status). J Epidemiol Community Health 2000;54:299-305.

15. Gornick ME, Eggers PW, Reilly TW, Mentnech RM, Fitterman LK, Kucken LE et al. Effects of race and income on mortality and use of services among Medicare beneficiaries. N Engl J Med 1996;335:791-9.

16. Turrell G, Kavanagh AM. Socio-economic pathways to diet: modelling the association between socioeconomic position and food purchasing behaviour. Public Health Nutr 2006;9:375-83.

17. Schrijvers CT, Stronks K, van de Mheen HD, Mackenbach JP. Explaining educational differences in mortality: the role of behavioral and material factors. Am J Public Health 1999;89:535-40. 